\title{
Somatic mutation profiling of liver and biliary cancer by targeted next generation sequencing
}

\author{
BO-LUN ZHANG ${ }^{1 *}, \mathrm{XU} \mathrm{JI}^{2 *}$, LING-XIANG YU ${ }^{2 *}, \mathrm{YUAN} \mathrm{GAO}^{2}$, \\ CHAO-HUI XIAO ${ }^{2}$, JIA LIU ${ }^{2}$, DE-XI ZHAO ${ }^{2}$, YI LE $^{2}$, GUANG-HAO DIAO $^{2}$, JIA-YI SUN $^{2}$, \\ GAO-HUA LI ${ }^{2}$, GUANG-LIN LEI ${ }^{2}$, PENG YU ${ }^{2}$, RUI-LAN WANG ${ }^{2}$, JIAN-ZHONG WU $^{2}$, \\ PENG-HUI YANG ${ }^{2}$, JIN YAN $^{2}$, JING-YU LI $^{3}$, JIA-JIA XU ${ }^{3}$, SHAO-GENG ZHANG ${ }^{2}$ and HU TIAN ${ }^{4}$
}

\begin{abstract}
${ }^{1}$ Department of General Surgery, Clinical Medical College of Weifang Medical University, Weifang, Shandong 261042; ${ }^{2}$ Department of Hepatobiliary Surgery, 302 Military Hospital of China, Beijing 100039; ${ }^{3}$ Institute of Precision Medicine, 3D Medicines, Inc., Shanghai 201114; ${ }^{4}$ Department of Hepatobiliary Surgery, Shandong Provincial Qianfoshan Hospital, Shandong University, Jinan, Shandong 250014, P.R. China
\end{abstract}

Received December 13, 2017; Accepted July 13, 2018

DOI: $10.3892 / 01.2018 .9371$

\begin{abstract}
Liver and biliary cancers are highly lethal cancer types lacking effective treatments. The somatic mutations, particularly those with low mutant allele frequencies, in Chinese patients with liver and biliary cancer have not been profiled, and the frequency of patients benefiting from targeted therapy has not been studied. The present study evaluated the tumor tissues of 45 Chinese patients with hepatocellular carcinoma (HCC) and 12 Chinese patients with biliary tract cancer (BTC) by targeted next generation sequencing, with an average coverage of $639 x$, to identify alterations in 372 cancer-related genes. A total of 263 variants were identified in 139 genes, with $85.6 \%$ of these variants not previously reported in the Catalogue Of Somatic Mutations In Cancer database, and the mutation profile was different from the current datasets, including The Cancer Genome Atlas dataset and the National Cancer Center Japan (NCC_JP) dataset. Patients with hepatitis $\mathrm{B}$ virus (HBV) infection harbored more mutations than those without HBV infection, and the mutations in HBV carriers occurred preferentially in genes involved in vascular endothelial growth factor signaling pathways. Mutations in fibroblast
\end{abstract}

Correspondence to: Dr Shao-Geng Zhang, Department of Hepatobiliary Surgery, 302 Military Hospital of China, 100 West Fourth Ring Road, Beijing 100039, P.R. China

E-mail: zhangsg302@hotmail.com

Dr Hu Tian, Department of Hepatobiliary Surgery, Shandong Provincial Qianfoshan Hospital, Shandong University, 16766 Jingshi Road, Jinan, Shandong 250014, P.R. China

E-mail: 15853161228@163.com

*Contributed equally

Key words: hepatocellular carcinoma, biliary tract cancer, somatic mutation, next generation sequencing, hepatitis B virus growth factor and RAS signaling pathways were enriched in patients with cirrhosis, and alterations in interleukin and transforming growth factor signaling pathways were more frequently identified in individuals with abnormal bilirubin expression. Of all the patients, $7 \%$ exhibited variants in the target of sorafenib, and $42 \%$ harbored variants in the targets of drugs that have been approved to treat other types of cancer. These findings indicate diverse HCC/BTC variants patterns in different populations, and that the mutation load and patterns are correlated with clinical features. Further clinical studies are now warranted to evaluate the efficacies of other targeted drugs besides sorafenib in the treatment of patients with liver and biliary cancer.

\section{Introduction}

Liver cancer is the third leading cause of cancer-associated mortality worldwide (1). The incidence of liver cancer is high in East Asia and Africa (1-4), and the prognosis is generally poor. Hepatocellular carcinoma (HCC) is the most common form of liver cancer (1). Advances in sequencing technologies have enabled the examination of liver cancer genomes at high resolution. Whole genome sequencing (WGS) and whole exome sequencing (WES) have been used to identify genomic alterations in liver cancers (5), and have identified mutations that frequently occur in liver cancer. Since cancer is heterogeneous, it is difficult for WGS or WES to identify variants at low frequencies due to the relatively low coverage of sequencing $(<200 x)$. Investigating liver cancer genomes using a more sensitive method is therefore required to identify more detailed patterns of somatic variants.

Biliary tract cancer (BTC) is the second most common primary hepatobiliary cancer after HCC (6). BTC typically follows an aggressive disease course associated with a poor clinical outcome. Surgery is the only curative treatment, but the majority of patients present with advanced disease and therefore have a limited survival probability. Gemcitabine and cisplatin-based chemotherapy has been the only widely 
accepted standard systemic therapy (7). Reports on somatic mutations in BTC are rare, and recurrent mutations in BTC have not been identified to date. An understanding of the molecular characteristics of BTC may allow for the clinical development of therapies targeting actionable alterations, with the ultimate aim of improving clinical outcome. For instance, with the aid of next generation sequencing (NGS), actionable mutations including those in isocitrate dehydrogenase 1 , fibroblast growth factor (FGF) receptor (FGFR)-2, BRAF and human epidermal growth factor receptor 2 have been identified as candidates for targeted therapeutics (8).

Hepatitis B virus (HBV) infection, cirrhosis, fatty liver and alcohol intake are well-known risk factors for liver cancer (2-4). It has been reported that HBV has preferences in host genome integration sites (9-11), contributing toward genomic instability and hepatocarcinogenesis (12). HBV not only creates an environment that promotes the tumorigenic process, but also directs interactions among signaling cascades to further enhance the process (13). For example, the expression of viral protein $\mathrm{HBx}$ may promote the transcription of insulin-like growth factor (IGF)-2, transforming growth factor (TGF)- $\beta$, vascular endothelial growth factor (VEGF) and yes-associated protein 1 (14-17), and enhance mechanistic target of rapamycin (mTOR), Wnt/ $\beta$-catenin and Hedgehog signaling (17-19). However, it remains unclear whether these risk factors have any correlation with somatic variants in liver cancer.

The present study identified the somatic variants in liver cancer by targeted NGS at a depth of 639x, and studied variants relevant to $\mathrm{HBV}$, cirrhosis and bilirubin levels. The proportion of patients harboring potential targets of existing drugs for all cancer types was also analyzed.

\section{Patients and methods}

Patients. Tumor specimens and matched blood samples were obtained from 57 patients who were diagnosed with HCC (45) or BTC (12) at the 302 Military Hospital of China (Beijing, China) between December 2015 and August 2016. Clinical information, including age, sex, HBV infection status, hepatohistological grade, disease stage and previous treatment history were collected. The present study included 50 male and 7 female patients with the mean age of the patients being 52.1 years, ranging from 17 to 71 years. The present study was approved by the Independent Ethics Committee of the 302 Military Hospital of China. All the patients provided written informed consent for the genomic testing used for the present study. Specimens were evaluated by board-certified pathologists to identify tumor-bearing areas for DNA extraction. The characteristics of the patients are presented in Table I.

Targeted NGS. Tumor tissue was obtained from biopsy or surgery upon the initial diagnosis of cancer at the primary site, fixed in $10 \%$ neutral formalin buffer at room temperature for 48 to $72 \mathrm{~h}$ and embedded in paraffin. Tumor genomic DNA was extracted from formalin-fixed and paraffin-embedded tumor tissue blocks using QIAamp DNA FFPE Tissue kit (Qiagen GmbH, Hilden, Germany), according to the manufacturer's protocols. In addition, tumor specimens were stained with $0.5 \%$ hematoxylin for $8 \mathrm{~min}$ and $0.5 \%$ eosin for $15 \mathrm{sec}$ at room temperature. A 4- $\mu \mathrm{m}$ section of a hematoxylin and eosin-stained slide was reviewed for pathology and only tissue slices with $>20 \%$ of tumor cells were further analyzed. Normal genomic DNA was extracted from peripheral blood mononuclear cells using QIAamp DNA Blood Mini kit (Qiagen $\mathrm{GmbH}$, Hilden, Germany), according to the manufacturer's protocols. Sequencing libraries for each sample were prepared followed by target capturing for 372 genes that are frequently rearranged in cancer. Massive parallel sequencing was then performed using Illumina NextSeq 500 (Illumina, Inc., San Diego, CA, USA), and samples with a mean sequencing depth of 639x were analyzed.

Data processing and analysis. Sequence data were mapped to the human genome (hg19) using BWA aligner v0.7.12 (http://bio-bwa.sourceforge.net/). PCR duplicate read removal and sequence metric collection were performed using Picard 1.130 (https://broadinstitute.github.io/picard/) and Samtools 0.1.19 (http://samtools.sourceforge.net/). Base substitution analysis, indel analysis, copy number analysis and rearrangement analysis were performed using variants called pipelines developed by 3D Medicines, Inc (Shanghai, China). All variants were verified by visually checking Integrative Genomics Viewer images. The differences in somatic variants between HCC and BTC were assessed by Student's t-test. For signaling pathway enrichment analysis, Student's t-tests were performed to calculate $\mathrm{P}$-values. $\mathrm{P}<0.05$ was considered to indicate a statistically significant difference.

\section{Results}

Somatic alterations in HCC and BTC. In the present study, 57 primary HCC/BTC tumors and matched blood mononuclear cells were analyzed by DNA sequencing targeting 372 cancer-related genes (Fig. 1). The average base pair coverage was above 500x and 200x for tumor tissues and blood mononuclear cells, respectively. In total, 263 variants were detected in 139 genes (Fig. 1A). A total of $69.1 \%$ of the mutated genes were identified in only 1 patient, and the number of genes altered in more than 6 patients (10\%) was $6(4.3 \%)$, indicating a diverse somatic mutation pattern in the tested samples (Fig. 1B). Of all 344 variants detected, 67.2, 18.6, 8.4 and $5.5 \%$ were single nucleotide variants (SNVs), copy number variants (CNVs), small insertions or deletions (INDELs) and splices, respectively (Fig. 1C). Only one gene fusion (diglyceride acyltransferase-ATM serine/threonine kinase) was identified. The detected SNVs, CNVs, INDELs and splices exhibited preferences to different sets of genes, and only one gene [tumor protein p53 (TP53)] was identified to have all four types of mutations in different individuals (Fig. 1D). Out of 129 genes that had SNVs, 107 genes (82.9\%) had SNVs only, and 16 genes (12.4\%) occurred in chromosome $3(\mathrm{P}=0.0018)$. There were 18 genes harboring INDELs, and 5 genes $(27.8 \%)$ had INDELs exclusively. For the 34 genes with CNVs, 24 (70.6\%) were not detected to have SNVs, INDELs or splices, and 6 genes (17.6\%) occurred in chromosome $12(\mathrm{P}=0.018)$.

To determine whether the mutated genes in the patients with HCC/BTC were similar to those in published datasets, recurrent genes were compared in the current dataset. The Cancer 
Table I. Clinical information of the 57 patients with liver and biliary cancer.

\begin{tabular}{|c|c|c|c|c|c|}
\hline \multirow{2}{*}{\multicolumn{3}{|c|}{ biliary cancer. }} & & & \\
\hline & & & Characteristics & Category & Number \\
\hline Characteristics & Category & Number & \multirow{3}{*}{ Bilirubin, mg/l } & & 20 \\
\hline \multirow[t]{2}{*}{ Sex } & M & 50 & & $>10$ & $\begin{array}{l}20 \\
36\end{array}$ \\
\hline & $\mathrm{F}$ & 7 & & $\mathrm{~N} / \mathrm{A}$ & 1 \\
\hline \multirow{2}{*}{$\begin{array}{l}\text { Age at diagnosis, mean } \\
\text { years } \pm \mathrm{SD}\end{array}$} & & $52.1 \pm 10.6$ & \multirow[t]{4}{*}{ Platelet } & $<100$ & 9 \\
\hline & & & & $100-300$ & 43 \\
\hline \multirow[t]{3}{*}{ BMI index } & $<18.5$ & 2 & & $>300$ & 4 \\
\hline & $18.5-23.9$ & 24 & & $\mathrm{~N} / \mathrm{A}$ & 1 \\
\hline & $>23.9$ & 31 & \multirow[t]{4}{*}{$\mathrm{AFP}(\mathrm{ng} / \mathrm{ml})$} & $<25$ & 34 \\
\hline \multirow[t]{4}{*}{ Smoking } & Yes & 21 & & $25-500$ & 11 \\
\hline & Occasionally & 3 & & $>500$ & 11 \\
\hline & No & 31 & & $\mathrm{~N} / \mathrm{A}$ & 1 \\
\hline & $\mathrm{N} / \mathrm{A}$ & 2 & \multirow[t]{3}{*}{ ALT } & $0-40$ & 36 \\
\hline \multirow[t]{4}{*}{ Alcohol } & Yes & 15 & & $>40$ & 19 \\
\hline & Occasionally & 5 & & $\mathrm{~N} / \mathrm{A}$ & 2 \\
\hline & No & 35 & \multirow[t]{2}{*}{ Child-Pugh classification } & $0 / \mathrm{A}$ & 52 \\
\hline & $\mathrm{N} / \mathrm{A}$ & 2 & & $\mathrm{~B} / \mathrm{C} / \mathrm{D}$ & 1 \\
\hline \multirow[t]{2}{*}{ HBV } & Yes & 42 & & $\mathrm{~N} / \mathrm{A}$ & 4 \\
\hline & No & 15 & \multirow[t]{3}{*}{ BCLC } & $0 / \mathrm{A}$ & 12 \\
\hline \multirow[t]{2}{*}{ Alcoholic hepatitis } & Yes & 5 & & $\mathrm{~B}$ & 23 \\
\hline & No & 52 & & $\mathrm{C}$ & 16 \\
\hline \multirow[t]{3}{*}{ Fatty liver } & Yes & 3 & \multirow{6}{*}{ Stage } & $\mathrm{N} / \mathrm{A}$ & 6 \\
\hline & No & 53 & & I & 2 \\
\hline & $\mathrm{N} / \mathrm{A}$ & 1 & & II & 28 \\
\hline Cirrhosis and liver fibrosis & Yes & 41 & & III & 17 \\
\hline & No & 15 & & IV & 7 \\
\hline & $\mathrm{N} / \mathrm{A}$ & 1 & & $\mathrm{~N} / \mathrm{A}$ & 3 \\
\hline Family cancer history & Yes & 27 & Lesion & Primary & 52 \\
\hline & No & 30 & & Secondary & 2 \\
\hline Hepatectomy surgery & Yes & 51 & & $\mathrm{~N} / \mathrm{A}$ & 3 \\
\hline & No & 3 & Nodules & Single & 42 \\
\hline & $\mathrm{N} / \mathrm{A}$ & 3 & & Multiple & 14 \\
\hline ECOG score & 0 & 52 & & $\mathrm{~N} / \mathrm{A}$ & 1 \\
\hline & 1 & 4 & Number of tumors & 1 & 42 \\
\hline & $\mathrm{N} / \mathrm{A}$ & 1 & & $>1$ & 7 \\
\hline Metastases & Yes & 6 & & $\mathrm{~N} / \mathrm{A}$ & 8 \\
\hline & No & 50 & Microvascular invasion & Yes & 44 \\
\hline & $\mathrm{N} / \mathrm{A}$ & 1 & (tumor thrombus) & No & 9 \\
\hline Degree of differentiation & Undifferentiated & 0 & & $\mathrm{~N} / \mathrm{A}$ & 4 \\
\hline & Low & 5 & Large vascular invasion (tumor & Yes & 4 \\
\hline & Middle & 49 & thrombus) & No & 49 \\
\hline & High & 0 & & $\mathrm{~N} / \mathrm{A}$ & 4 \\
\hline & $\mathrm{N} / \mathrm{A}$ & 3 & Portal vein invasion (tumor & Yes & 9 \\
\hline Largest diameter of the & $<2$ & 4 & thrombus) & No & 44 \\
\hline tumor, $\mathrm{cm}$ & $2-5$ & 22 & & $\mathrm{~N} / \mathrm{A}$ & 4 \\
\hline & $5-10$ & 18 & Peripheral nerve invasion & Yes & 4 \\
\hline & $\geq 10$ & 9 & & No & 49 \\
\hline & NA & 4 & & $\mathrm{~N} / \mathrm{A}$ & 4 \\
\hline Albumin, g/l & $<35$ & 6 & $\overline{a n g}$ & & \\
\hline & $35-50$ & 49 & SD, standard deviation; BMI, bod & ass index; HB & hepatitis B \\
\hline & $>50$ & 1 & $\begin{array}{l}\text { virus; AFP, } \alpha \text {-fetoprotein; ALT, a } \\
\text { Barcelona Clinic Liver Cancer; NA }\end{array}$ & $\begin{array}{l}\text { e aminotrans } \\
\text { available. }\end{array}$ & Ise; BCLC, \\
\hline & N/A & 1 & & & \\
\hline
\end{tabular}

Table I. Continued. 
A

\begin{tabular}{ccccc}
\hline $\begin{array}{c}\text { Patient } \\
\text { no. }\end{array}$ & $\begin{array}{c}\text { Mutated gene no. } \\
\text { (SNV \& indel \& splicing) }\end{array}$ & $\begin{array}{c}\text { Variants no. } \\
\text { (SNV \& indel \& splicing) }\end{array}$ & $\begin{array}{c}\text { Cosmic } \\
\text { reported }\end{array}$ & Novel mutation no. \\
\hline 57 & 139 & 263 & 38 & 225 \\
\hline
\end{tabular}

B

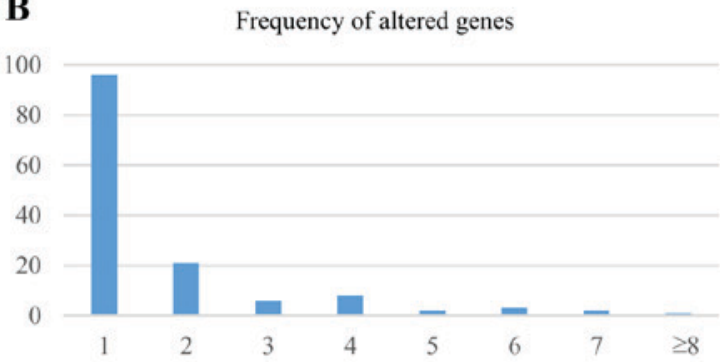

D

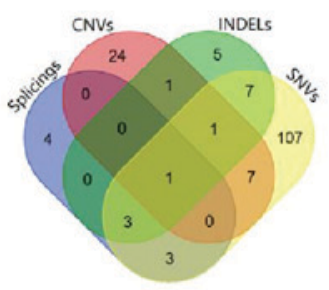

E

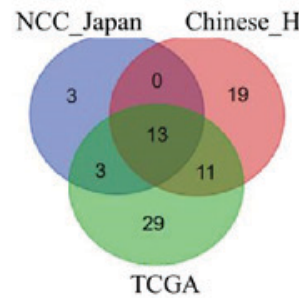

C

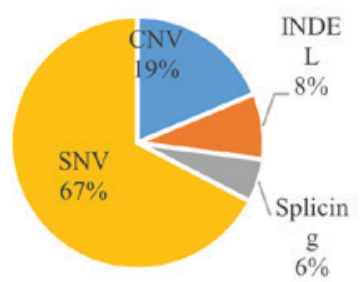

$\mathbf{F}$

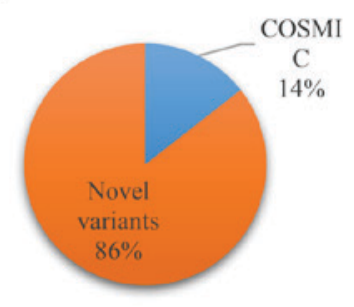

G

Figure 1. Somatic alterations in HCC and BTC. (A) In total, 263 variants were detected in 139 genes in the 57 patients with HCC/BTC. Of all variants detected, 225 were novel variants. (B) The comparison of mutated genes among TCGA, NCC_JP and the current HCC/BTC datasets. (C) The frequency of altered genes in the patients. (D) Of all 344 variants detected, 67.2, 18.6, 8.4 and 5.5\% were SNVs, CNVs, INDELs and splices, respectively. (E) Genes with different types of mutation. (F) Of all variants detected, $85.6 \%$ had not previously been reported in the COSMIC database. (G) The heat-map for different types of variants in the patients. HCC, hepatocellular carcinoma; BTC, biliary tract cancer; SNVs, single nucleotide variants; CNVs, copy number variants; INDELs, small insertions or deletions.

Genome Atlas (TCGA) dataset and the National Cancer Center Japan (NCC_JP) dataset. Notably, only 13 genes were shared across all three datasets (Fig. 1E). TP53 (64.9\%) and catenin- $\beta 1$ (CTNNB1; 7.0\%) were two of the genes that appeared among the 
A

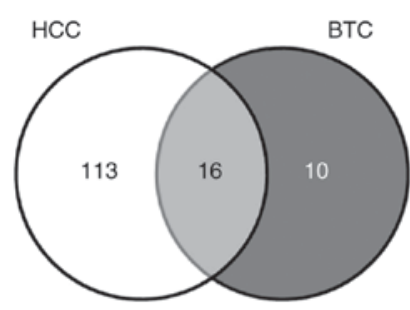

B

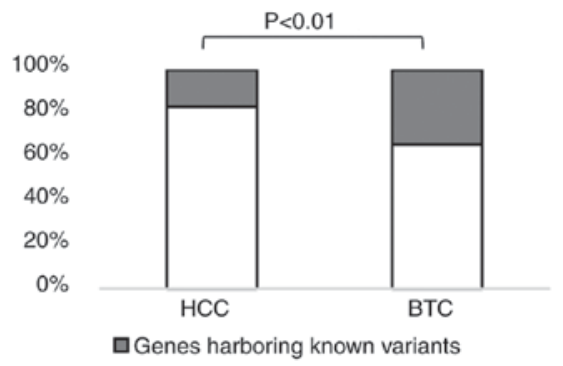

Genes harboring novel variants

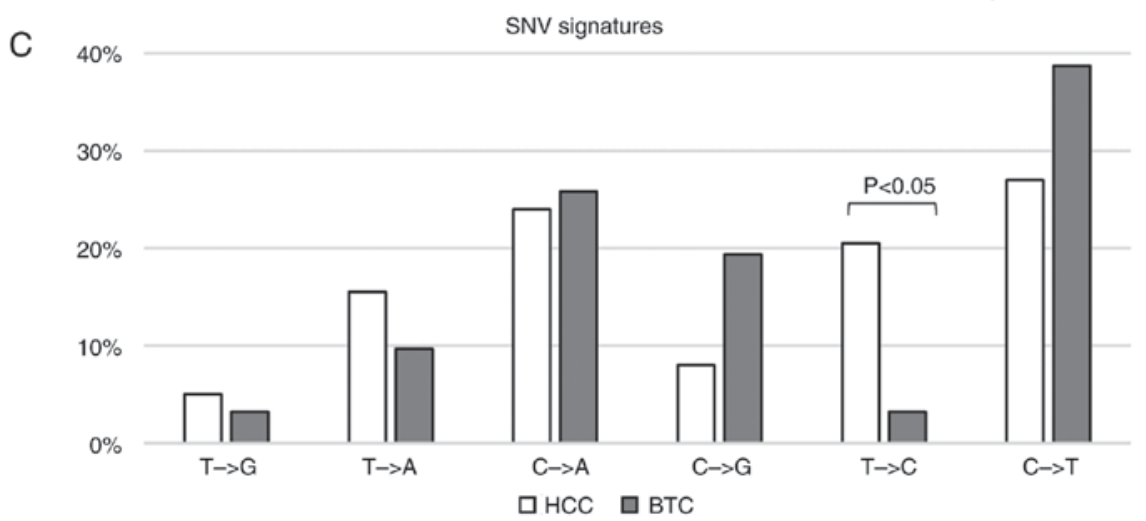

Figure 2. Differences in somatic variants in HCC and BTC. (A) Number of genes mutated in HCC and BTC. (B) The percentage of gene harboring novel variants in the two types of cancer. In HCC samples, $83.2 \%$ of the mutated genes harbored novel variants, which was significantly higher than that in BTC samples (65.9\%, binomial P<0.01). (C) The SNVs in HCC and BTC. SNVs in the two types of cancer share similar alteration signatures except for T $>$ C, which more frequently occurred in HCC (binomial P<0.05). HCC, hepatocellular carcinoma; BTC, biliary tract cancer; SNVs, single nucleotide variants; CNVs, copy number variants.

most frequently mutated genes in all three datasets. This finding is consistent with the data reported by Kan et al (5). Low-density lipoprotein receptor-related protein 1B (LRP1B; 12.3\%) and retinoblastoma gene (RB1; 12.3\%) were another two genes that were frequently mutated in the tested samples. Notably, the mutation rate of LRP1B in TCGA dataset was markedly higher compared with that in the NCC_JP dataset, whereas RB1 exhibited the opposite pattern. These results indicated diverse HCC/BTC variant patterns among different populations.

Of all the variants detected, $85.6 \%$ had not previously been reported in the Catalogue Of Somatic Mutations In Cancer (COSMIC) database (Fig. 1A and F). These novel variants were distributed across $96.5 \%$ (55/57) of the patients and as $95.0 \%(132 / 139)$ of the mutated genes, suggesting the existence of a dynamic mutation behavior in HCC/BTC (Fig. 1G).

$H C C$ vs. BTC. To identify the differences in somatic variants in $\mathrm{HCC}$ and BTC, the mutated genes in these two types of cancer were initially compared. As depicted in Fig. 2A, 16 genes were mutated in HCC and BTC. Of all the mutated genes, $11.5 \%$ of the genes were mutated in HCC and BTC. In the HCC samples, $83.2 \%$ of the mutated genes harbored novel variants, which was significantly higher than that in the BTC samples (65.9\%; binomial $\mathrm{P}<0.01$; Fig. 2B).

It has been reported that $\mathrm{SNV}$ signatures are diverse in different types of cancer (20). To determine the mutation signature differences in HCC and BTC, the nucleotide alteration patterns between HCC and BTC were calculated and compared. SNVs in these two types of cancer shared similar alteration signatures except for $\mathrm{T}>\mathrm{C}$, which more frequently occurred in HCC (Fig. 2C).
Variants relevant to $H B V$. Among the 57 tested patients, 42 were HBV carriers and 15 were not (Table I). Only 26 (16.4\%) genes were mutated in patients regardless of their HBV infection status (Fig. 3A). Gene ontology analysis revealed that genes mutated in $\mathrm{HBV}$ carriers were enriched in the VEGF, integrin and insulin/IGF signaling pathways $(\mathrm{P}<0.001$; Fig. 3B). Among the genes involved in these signaling pathways, KRAS proto-oncogene and phosphatase and tensin homolog are the genes that were mutated in HBV carriers and non-HBV carriers. Other genes in these signaling pathways that were exclusively mutated in HBV carriers included VEGFA, RAF1, protein tyrosine kinase 2, protein kinase c iota type (PRKCI), phospholipase C $\gamma 2$ (PLCG2), polycystin 2, phosphoinositide-3-kinase (PIK3) regulatory subunit 2, PIK3 catalytic subunit $\gamma$ (PIK3CG), PIK3C- $\delta$ (PIK3CD), PIK3C- $\alpha$ (PIK3CA), PIK3C2- $\beta$ (PIK3C2B), mitogen-activated protein kinase (MAPK) kinase 1 (MAP2K1), MAPK kinase kinase 1 (MAP3K1), HRAS proto-oncogene, Fms-related tyrosine kinase 4, LCK proto-oncogene, insulin receptor substrate 2, IGF2, IGF1 receptor, TSC1 and TSC2. In addition, the average number of variants per sample in HBV carriers was higher than that in non-HBV carriers, and this trend was more significant with novel variants (Table II). These results indicated that patients with HBV harbored more mutations than those without $\mathrm{HBV}$, and that $\mathrm{HBV}$ infection may correlate with mutations in angiogenesis and cell cycle-related signaling pathways.

Variants associated with cirrhosis/liver fibrosis. Patients with liver carcinoma are frequently diagnosed with cirrhosis, which has a strong correlation with HBV infection and chronic 
A

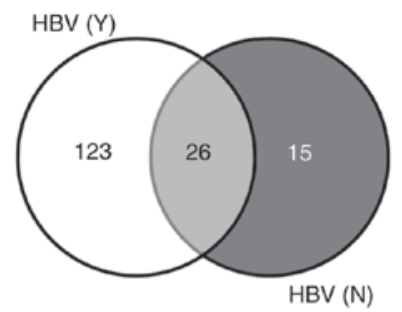

C

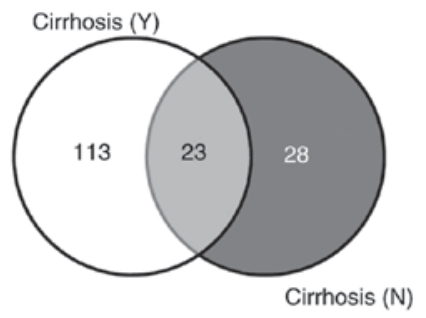

E

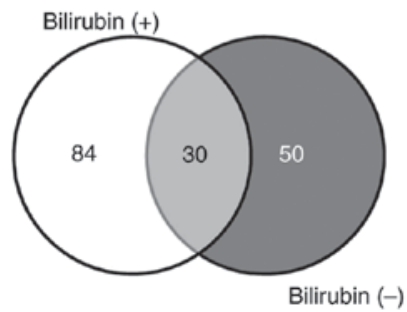

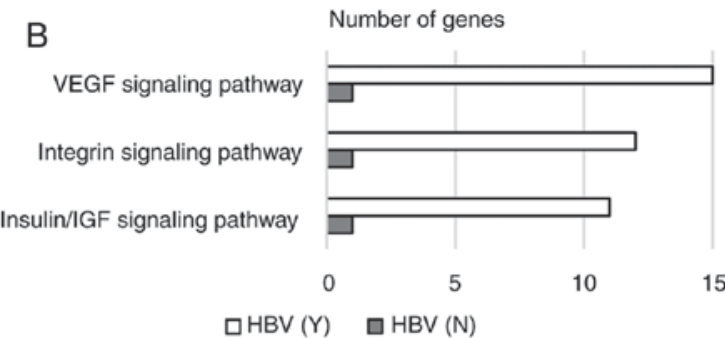

D

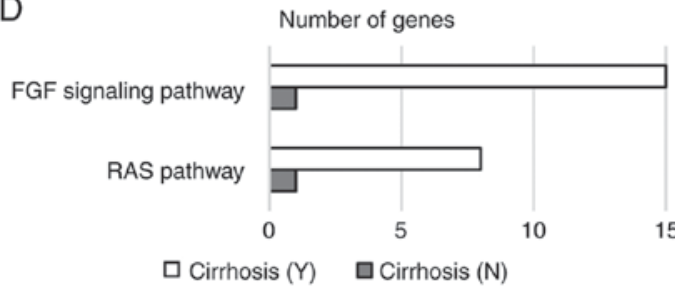

$\mathrm{F}$

Interleukin signaling pathway

TGF signaling pathway

Number of genes

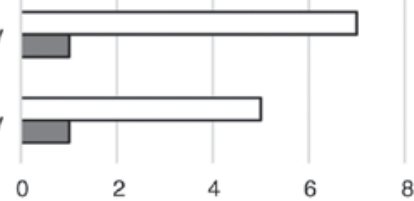

$\square$ Bilirubin (+) $\square$ Bilirubin (-)

Figure 3. Variants relevant to clinical characteristics. (A) Number of genes mutated in HBV carriers and non-carriers. (B) Gene ontology analysis revealed that genes mutated in HBV carriers were enriched in the VEGF, integrin and insulin/IGF signaling pathways $(\mathrm{P}<0.001)$. (C) Number of genes mutated in patients with or without cirrhosis. (D) Signaling pathway enrichment in cirrhosis patients $(\mathrm{P}<0.01)$. (E) Number of genes mutated in patients with normal or abnormal bilirubin levels. (F) Signaling pathway enrichment in patients with abnormal bilirubin levels $(\mathrm{P}<0.05)$. HBV, hepatitis B virus; VEGF, vascular endothelial growth factor; FGF, fibroblast growth factor; IGF, insulin-like growth factor; TGF, transforming growth factor.

hepatitis (21). In the present study, 41 (71.9\%) patients were diagnosed with cirrhosis. Patients with cirrhosis and those without cirrhosis shared 23 mutated genes, including KRAS (Fig. 3C). Genes exclusively mutated in patients with cirrhosis were enriched in the FGF signaling pathway and the RAS pathway $(\mathrm{P}<0.01$; Fig. 3D). These two signaling pathways share numerous genes, including PIK3CG, PIK3CD, PIK3CA, MAP3K1, MAP2K1, RAF1, KRAS and HRAS, but not FGF3, FGF4, FGFR1, FGFR substrate 2, PIK3C2B, PLCG2 and PRKCI, which are involved in the FGF signaling pathway only. Similar to HBV carriers, patients with cirrhosis also harbored significantly more novel variants than those without cirrhosis (Table II).

Variants relevant to bilirubin level. In the present study, 20 patients had a normal level of bilirubin, while 36 patients exhibited abnormal bilirubin levels (Table II). Genes mutated in these two populations were different, although $18.3 \%$ of the genes were shared by the two groups (Fig. 3E). Altered genes in patients with abnormal bilirubin levels were enriched in the TGF and interleukin signaling pathways $(\mathrm{P}<0.05$; Fig. $3 \mathrm{~F})$. There was no correlation between mutation burden and bilirubin abnormality (Table II).

Variants relevant to targeted drugs. To identify the number of patients with liver and biliary carcinoma that harbored drug-targetable mutations, the mutated genes that have been approved to be the targets of existing drugs were analyzed. As depicted in Fig. 4, 7\% of the patients could possibly benefit from sorafenib, which is the only drug that has been approved to treat patients with advanced HCC (22). A total of $42 \%$ of the patients had mutations that were targets of everolimus/temsirolimus (26\%), olaparib (7\%), palbociclib (5\%), crizotinib/cabozantinib (2\%) or trametinib/cobimetinib (2\%). Notably, the number of patients with mutations targetable by everolimus/temsirolimus was markedly higher than the number of patients with mutations targetable by sorafenib, indicating that these drugs may have promise in $\mathrm{HCC} / \mathrm{BTC}$ therapy.

\section{Discussion}

HCC and BTC are two different types of tumor. They are morphologically distinct from each other, and vary markedly in clinical features: For example, jaundice is a prominent symptom of BTC but not of HCC; and carbohydrate antigen 19-9 is a widely used marker in diagnosing BTC, while $\alpha$-fetoprotein is the gold standard in HCC diagnostics. At the molecular level, carcinogenesis is a complex process resulting from the accumulation of genetic alterations of various cancer-driver genes. The majority of cancer types, including HCC and BTC, are genetically and biologically heterogeneous, which causes the response of patients with the same type of cancer to differ when administered with the same treatment, due to substantial 
Table II. Association between clinical characteristics and number of mutations.

\begin{tabular}{|c|c|c|c|c|c|c|}
\hline Characteristic & Category & $\begin{array}{l}\text { Sample } \\
\text { number }\end{array}$ & $\begin{array}{l}\text { Variants } \\
\text { number }\end{array}$ & $\begin{array}{c}\text { Novel variants } \\
\text { number }\end{array}$ & $\begin{array}{l}\text { Variants per } \\
\text { sample }\end{array}$ & $\begin{array}{c}\text { Novel variants } \\
\text { per sample }\end{array}$ \\
\hline \multirow[t]{2}{*}{ Sex } & Male & 50 & 244 & 195 & 4.9 & 3.9 \\
\hline & Female & 7 & 35 & 30 & 5.0 & 4.3 \\
\hline \multirow[t]{2}{*}{ Smoking } & Yes & 21 & 94 & 75 & 4.5 & 3.6 \\
\hline & Occasionally/no & 34 & 181 & 148 & 5.3 & 4.4 \\
\hline \multirow[t]{2}{*}{ Alcohol } & Yes & 15 & 66 & 52 & 4.4 & 3.5 \\
\hline & Occasionally/no & 40 & 209 & 171 & 5.2 & 4.3 \\
\hline \multirow[t]{2}{*}{$\mathrm{HBV}$} & Yes & 42 & 232 & 196 & 5.5 & 4.7 \\
\hline & No & 15 & 47 & 29 & 3.1 & 1.9 \\
\hline \multirow[t]{2}{*}{ Alcoholic hepatitis } & Yes & 5 & 15 & 10 & 3.0 & 2.0 \\
\hline & No & 52 & 264 & 215 & 5.1 & 4.1 \\
\hline \multirow[t]{2}{*}{ Fatty liver } & Yes & 3 & 13 & 10 & 4.3 & 3.3 \\
\hline & No & 53 & 261 & 211 & 4.9 & 4.0 \\
\hline \multirow{2}{*}{$\begin{array}{l}\text { Cirrhosis and liver } \\
\text { fibrosis }\end{array}$} & Yes & 41 & 210 & 174 & 5.1 & 4.2 \\
\hline & No & 15 & 64 & 47 & 4.3 & 3.1 \\
\hline \multirow{2}{*}{$\begin{array}{l}\text { Family cancer } \\
\text { history }\end{array}$} & Yes & 27 & 146 & 116 & 5.4 & 4.3 \\
\hline & No & 30 & 133 & 109 & 4.4 & 3.6 \\
\hline \multirow[t]{2}{*}{ Metastases } & Yes & 6 & 25 & 20 & 4.2 & 3.3 \\
\hline & No & 50 & 249 & 201 & 5.0 & 4.0 \\
\hline \multirow{2}{*}{$\begin{array}{l}\text { Degree of } \\
\text { differentiation }\end{array}$} & Undifferentiated/low & 5 & 11 & 7 & 2.2 & 1.4 \\
\hline & Middle/high & 49 & 251 & 205 & 5.1 & 4.2 \\
\hline \multirow{2}{*}{$\begin{array}{l}\text { Largest diameter of } \\
\text { the tumor, } \mathrm{cm}\end{array}$} & $<5$ & 26 & 125 & 102 & 4.8 & 3.9 \\
\hline & $\geq 5$ & 27 & 124 & 99 & 4.6 & 3.7 \\
\hline \multirow{2}{*}{ Bilirubin, mg/l } & $1-10$ & 20 & 108 & 90 & 5.4 & 4.5 \\
\hline & $>10$ & 36 & 166 & 131 & 4.6 & 3.6 \\
\hline \multirow[t]{2}{*}{$\mathrm{AFP}, \mathrm{ng} / \mathrm{ml}$} & $<25$ & 34 & 165 & 128 & 4.9 & 3.8 \\
\hline & $\geq 25$ & 22 & 109 & 93 & 5.0 & 4.2 \\
\hline \multirow[t]{2}{*}{ ALT } & $0-40$ & 36 & 197 & 160 & 5.5 & 4.4 \\
\hline & $>40$ & 19 & 72 & 56 & 3.8 & 3.0 \\
\hline \multirow{2}{*}{$\begin{array}{l}\text { Child-Pugh } \\
\text { classification }\end{array}$} & 0/A & 52 & 256 & 208 & 4.9 & 4.0 \\
\hline & $\mathrm{B} / \mathrm{C} / \mathrm{D}$ & 1 & 0 & 0 & 0.0 & 0.0 \\
\hline \multirow[t]{2}{*}{ BCLC } & 0/A & 12 & 64 & 55 & 5.3 & 4.6 \\
\hline & $\mathrm{B} / \mathrm{C}$ & 39 & 197 & 159 & 5.1 & 4.1 \\
\hline \multirow[t]{2}{*}{ Stage } & $\mathrm{I} / \mathrm{II}$ & 30 & 173 & 142 & 5.8 & 4.7 \\
\hline & III/IV & 24 & 100 & 79 & 4.2 & 3.3 \\
\hline \multirow[t]{2}{*}{ Lesion } & Primary & 52 & 258 & 208 & 5.0 & 4.0 \\
\hline & Secondary & 2 & 8 & 7 & 4.0 & 3.5 \\
\hline \multirow[t]{2}{*}{ Nodules } & Single & 42 & 198 & 158 & 4.7 & 3.8 \\
\hline & Multiple & 14 & 76 & 63 & 5.4 & 4.5 \\
\hline \multirow[t]{2}{*}{ Number of tumors } & 1 & 42 & 198 & 158 & 4.7 & 3.8 \\
\hline & $>1$ & 7 & 39 & 30 & 5.6 & 4.3 \\
\hline \multirow{2}{*}{$\begin{array}{l}\text { Microvascular invasion } \\
\text { (tumor thrombus) }\end{array}$} & Yes & 44 & 215 & 176 & 4.9 & 4.0 \\
\hline & No & 9 & 40 & 30 & 4.4 & 3.3 \\
\hline & Yes & 4 & 10 & 7 & 2.5 & 1.8 \\
\hline (tumor thrombus) & No & 49 & 245 & 199 & 5.0 & 4.1 \\
\hline Portal vein invasion & Yes & 9 & 25 & 19 & 2.8 & 2.1 \\
\hline (tumor thrombus) & No & 44 & 230 & 187 & 5.2 & 4.3 \\
\hline Peripheral nerve invasion & Yes & 4 & 7 & 2 & 1.8 & 0.5 \\
\hline & No & 49 & 248 & 204 & 5.1 & 4.2 \\
\hline
\end{tabular}

HBV, hepatitis B virus; AFP, $\alpha$-fetoprotein; ALT, alanine aminotransferase; BCLC, Barcelona Clinic Liver Cancer. 
variations in the molecular mutations underlying carcinogenesis. Accumulating studies have identified the presence of common molecular mutations beyond those of the traditionally viewed histological tumor subtypes (23). It has been demonstrated that the expression of SLC22A1 variants may affect the response of HCC and cholangiocarcinoma to sorafenib (24). Additionally, a recent study identified that Asian patients with either HCC or cholangiocarcinoma, though clinically treated as separate entities, share common molecular subtypes with similar actionable drivers (25). Clinically, numerous trials are ongoing for HCC and BTC, including a single arm phase II trial of gemcitabine and oxaliplatin with erlotinib (Tarceva) for the treatment of patients with HCC and BTC (NCT00832637), a phase II trial of BBI503 in adult patients with advanced hepatobiliary cancer (NCT02232633), and phase I and II trials of combined immune checkpoint inhibition in combination with ablative therapies in patients with $\mathrm{HCC}$ or BTC (NCT02821754).

In the human genome, there are six patterns of base substitution $(\mathrm{C}>\mathrm{A}, \mathrm{C}>\mathrm{G}, \mathrm{C}>\mathrm{T}, \mathrm{T}>\mathrm{A}, \mathrm{T}>\mathrm{C}$ and $\mathrm{T}>\mathrm{G})$. Base substitution patterns are affected by exogenous or endogenous mutagens, including oxidative stress, exposure to chemicals or ultraviolet radiation and defects in the DNA repair machinery (26). It has been reported that $\mathrm{C}>\mathrm{T}$ and $\mathrm{T}>\mathrm{C}$ substitutions are dominant in HCC (27). In line with these findings, the results of the present study demonstrated that $\mathrm{C}>\mathrm{T}(27 \%), \mathrm{C}>\mathrm{A}(24 \%)$ and $\mathrm{T}>\mathrm{C}(21 \%)$ were the top 3 base substitutions in HCC cases (Fig. 2C). In addition, T>A transitions also frequently occurred (16\%) in the HCC cases, which to the best of our knowledge has not been reported previously. A previous study revealed that $\mathrm{C}>\mathrm{T}$ transitions were dominant in cholangiocarcinoma with liver fluke (28). Consistent with the results of this previous study, the most frequently occurring base substitutions in the present study were $\mathrm{C}>\mathrm{T}$ transitions (39\%). Furthermore, $26 \%$ of the base substitutions were $\mathrm{C}>\mathrm{A}$ transitions, indicating that $\mathrm{C}>\mathrm{A}$ alterations may be another signature of BTC substitutions. Unlike $\mathrm{HCC}$, the $\mathrm{T}>\mathrm{C}$ transitions were rarely identified in $\mathrm{BTC}(\mathrm{P}<0.05)$, revealing distinct mutation signatures in $\mathrm{HCC}$ and BTC.

A previous WGS study of 88 HCC cases identified an average somatic mutation rate of 3.69 per $\mathrm{Mb}$, which is mid-range among all types of cancer (5). In the present study, the average somatic mutation rate was 4.89 per sample, which is equal to 3.95 per Mb. Notably, HBV-positive cases exhibited a significantly higher mutation rate (5.5 per sample), compared with HBV-negative cases (3.1 per sample; Table II). This difference was even greater for newly identified variants (4.7 vs. 1.9 per sample). As HBV infection causes genome instabilities and is associated with a poor prognosis of liver cancer, these findings confirmed that the presence of HBV infection is associated with the frequencies of mutations that lead to the complexity of liver cancer.

$\mathrm{HBV}$ is a DNA virus with a genome that integrates into the host genome. Studies have demonstrated that HBV integration in the telomerase reverse transcriptase, myeloid/lymphoid lineage 4, lysine methyltransferase $2 b$, cyclin E1 and fibronectin 1 genes is frequent in cases of $\operatorname{HCC}(11,29,30)$. It was reported that genes involved in the WNT/CTNNB1 and Janus kinase/signal transducer and activator of transcription pathways were frequently mutated in HBV-positive HCC cases (30). By contrast to these findings, the present study demonstrated that genes in the VEGF,

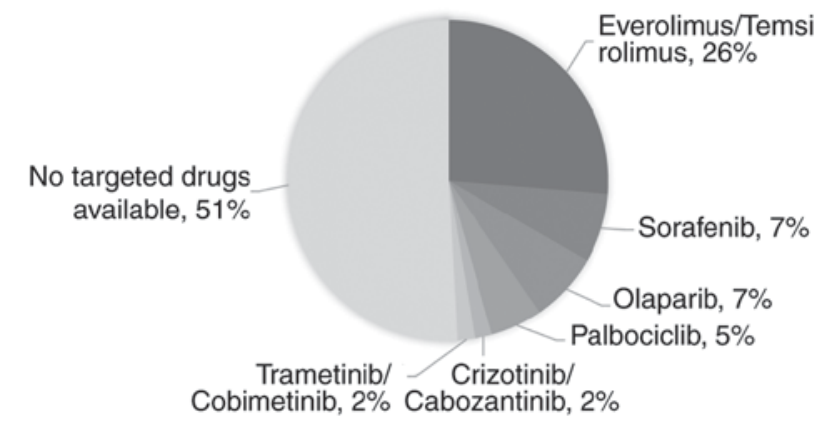

Figure 4. Variants relevant to targeted drugs. In total, $7 \%$ of the patients could possibly benefit from sorafenib treatment, other $42 \%$ harbored variants in the targets of drugs that had been approved to treat other types of cancer.

integrin and insulin/IGF signaling pathways were frequently mutated in HBV-positive cases, but not in HBV-negative cases. Notably, a previous study reported that the expression of the HBV protein HBx can upregulate VEGF and hypoxia-inducible factor- $1 \alpha$ to induce the angiogenesis response (31). It was also reported that the HBx protein may serve roles in cell spreading by modulating the balance of cell adhesion (32). The results of the present study suggested that HBV infection may induce angiogenesis and cell adhesion changes through genomic alterations and expression of virus proteins. Further studies are required to determine the mechanisms underlying mutations in angiogenesis and cell adhesion genes caused by HBV infection. Frequent mutations in these signaling pathways in HBV-positive patients suggested that drugs targeting these pathways may be worthy of clinical trials in HBV-positive HCC patients.

At present, surgery remains the most effective treatment for patients with liver cancer. Sorafenib, a drug targeting VEGFA, has been approved for the treatment of advanced HCC (22). However, the results of the present study indicated that few patients $(7 \%)$ may benefit from this drug. Notably, approximately half $(42 \%)$ of the patients in the present study harbored target mutations of drugs that have been approved to treat other types of cancer. Certain drug targets, including mTOR pathway genes, occurred more frequently than the targets of sorafenib. Further clinical studies are warranted to evaluate the efficacies of these drugs in patients with liver cancer. Notably, $51 \%$ of patients in the present study did not harbor targets of any drugs. Studies with a larger cohort may elucidate the biomarkers that are more widespread in patients with liver cancer.

In recent years, advances in immunotherapy have provided novel therapeutic strategies for cancer patients with complicated cases. Immunotherapeutics, including antibodies that block programmed death receptor-1 (PD-1)/programmed death-ligand 1 (PD-L1) may induce durable responses across numerous types of tumor (33-36). However, the majority of biomarker-unselected patients will not respond to immunotherapy; therefore, there is an unmet requirement to determine biomarkers that will identify patients more likely to respond to PD-1/PD-L1 blockade, as well as other immunotherapeutics. Cancer is caused by the accumulation of somatic mutations, and high tumor mutational burden (TMB) may be a response biomarker for PD-1/PD-L1 blockade in tumors. It was demonstrated in non-small cell lung cancer that a higher TMB was associated with improved objective response, durable 
clinical benefit and progression-free survival (37). However, it is unclear whether TMB serves as a useful biomarker for predicting response to immunotherapy in HCC. In a recent phase 1/2 clinical trial (NCT01658878), the PD-1 inhibitor nivolumab was assessed for safety and efficacy in patients with advanced HCC. A manageable safety profile and durable objective responses indicated the potential of nivolumab for the treatment of advanced HCC (38). As indicated in the present study, HCC and BTC exhibit relatively high TMB compared with other tumors, and HBV carriers have an even higher mutation load. Therefore, further clinical studies are required to evaluate the efficacies of immunotherapy in $\mathrm{HCC}$ and BTC, particularly in HBV-positive HCC patients.

\section{Acknowledgements}

Not applicable.

\section{Funding}

No funding was received.

\section{Availability of data and materials}

The datasets used and/or analyzed during the current study are available from the corresponding author on reasonable request.

\section{Authors' contributions}

BLZ analyzed the somatic alterations in HCC and BTC and wrote the manuscript. XJ collected the samples and clinical information of the patients and wrote the manuscript. LXY identified the differences in somatic variants in HCC and BTC and wrote the manuscript. YG performed gene ontology analysis. C-HX conducted drug-targetable mutation analysis. JL collected the samples and clinical information of the patients. DXZ performed the pathway analysis. YL made correlation analysis between the informatic data and clinical information. GHD performed bioinformatics analysis of the targeted NGS data. JYS contributed to data interpretation and wrote the manuscript. GHL made correlation analysis between the informatic data and clinical information. GLL discussed the results and contributed toward data interpretation. PY detected the bilirubin, albumin and AFP levels of the patients. RLW performed bioinformatics analysis of the targeted NGS data. JZW conducted the HBV tests. PHY collected the samples and clinical information of the patients. JY detected the bilirubin, albumin and AFP levels of the patients. JYL constructed the sequencing libraries and performed NGS. JJX extracted genomic DNA from tumor tissue and peripheral blood mononuclear cell. SGZ conceived the study and participated in its design and coordination. HT conceived the study and participated in its design. All authors read and approved the final manuscript.

\section{Ethics approval and consent to participate}

The present study was approved by the Independent Ethics Committee of the 302 Military Hospital of China. All the patients provided written informed consent for the genomic testing used for the present study.

\section{Patient consent for publication}

Not applicable.

\section{Competing interests}

The authors declare that they have no competing interests.

\section{References}

1. Jemal A, Bray F, Center MM, Ferlay J, Ward E and Forman D: Global cancer statistics. CA Cancer J Clin 61: 69-90, 2011.

2. El-Serag HB: Epidemiology of viral hepatitis and hepatocellular carcinoma. Gastroenterology 142: 1264-1273.e1, 2012.

3. Forner A, Llovet JM and Bruix J: Hepatocellular carcinoma. Lancet 379: 1245-1255, 2012.

4. Shaib Y and El-Serag HB: The epidemiology of cholangiocarcinoma. Semin Liver Dis 24: 115-125, 2004.

5. Kan Z, Zheng H, Liu X, Li S, Barber TD, Gong Z, Gao H, Hao K, Willard MD, Xu J, et al: Whole-genome sequencing identifies recurrent mutations in hepatocellular carcinoma. Genome Res 23: 1422-1433, 2013.

6. Hennedige TP, Neo WT and Venkatesh SK: Imaging of malignancies of the biliary tract-an update. Cancer Imaging 14: 14, 2014.

7. Jain A, Kwong LN and Javle M: Genomic profiling of biliary tract cancers and implications for clinical practice. Curr Treat Options Oncol 17: 58, 2016.

8. Jain A and Javle M: Molecular profiling of biliary tract cancer: A target rich disease. J Gastrointest Oncol 7: 797-803, 2016.

9. Fujimoto A, Totoki Y, Abe T, Boroevich KA, Hosoda F, Nguyen HH, Aoki M, Hosono N, Kubo M, Miya F, et al: Whole-genome sequencing of liver cancers identifies etiological influences on mutation patterns and recurrent mutations in chromatin regulators. Nat Genet 44: 760-764, 2012.

10. Jiang Z, Jhunjhunwala S, Liu J, Haverty PM, Kennemer MI, Guan Y, Lee W, Carnevali P, Stinson J, Johnson S, et al: The effects of hepatitis B virus integration into the genomes of hepatocellular carcinoma patients. Genome Res 22: 593-601, 2012.

11. Sung WK, Zheng H, Li S, Chen R, Liu X, Li Y, Lee NP, Lee WH, Ariyaratne PN, Tennakoon C, et al: Genome-wide survey of recurrent $\mathrm{HBV}$ integration in hepatocellular carcinoma. Nat Genet 44: 765-769, 2012.

12. Zhao LH, Liu X, Yan HX, Li WY, Zeng X, Yang Y, Zhao J, Liu SP, Zhuang XH, Lin C, et al: Genomic and oncogenic preference of HBV integration in hepatocellular carcinoma. Nat Commun 7: 12992, 2016.

13. Yang P, Markowitz GJ and Wang XF: The hepatitis B virus-associated tumor microenvironment in hepatocellular carcinoma. Natl Sci Rev 1: 396-412, 2014.

14. Tang S, Hu W, Hu J, Wu S, Li J, Luo Y, Cao M, Zhou H and Jiang X: Hepatitis B virus $\mathrm{X}$ protein promotes $\mathrm{P} 3$ transcript expression of the insulin-like growth factor 2 gene via inducing hypomethylation of $\mathrm{P} 3$ promoter in hepatocellular carcinoma. Liver Int 35: 608-619, 2015.

15. Pan J, Clayton M and Feitelson MA: Hepatitis B virus X antigen promotes transforming growth factor-betal (TGF-betal) activity by up-regulation of TGF-betal and down-regulation of alpha2-macroglobulin. J Gen Virol 85: 275-282, 2004.

16. Yen CJ, Lin YJ, Yen CS, Tsai HW, Tsai TF, Chang KY, Huang WC, Lin PW, Chiang CW and Chang TT: Hepatitis B virus X protein upregulates mTOR signaling through IKK $\beta$ to increase cell proliferation and VEGF production in hepatocellular carcinoma. PLoS One 7: e41931, 2012.

17. Zhang T, Zhang J, You X, Liu Q, Du Y, Gao Y, Shan C, Kong G, Wang Y, Yang X, et al: Hepatitis B virus X protein modulates oncogene Yes-associated protein by CREB to promote growth of hepatoma cells. Hepatology 56: 2051-2059, 2012.

18. Hsieh A, Kim HS, Lim SO, Yu DY and Jung G: Hepatitis B viral $X$ protein interacts with tumor suppressor adenomatous polyposis coli to activate Wnt/ $\beta$-catenin signaling. Cancer Lett 300: 162-172, 2011 
19. Kim HY, Cho HK, Hong SP and Cheong J: Hepatitis B virus $X$ protein stimulates the Hedgehog-Gli activation through protein stabilization and nuclear localization of Gli1 in liver cancer cells. Cancer Lett 309: 176-184, 2011.

20. Alexandrov LB, Nik-Zainal S, Wedge DC, Aparicio SA, Behjati S, Biankin AV, Bignell GR, Bolli N, Borg A, Børresen-Dale AL, et al: Signatures of mutational processes in human cancer. Nature 500: 415-421, 2013.

21. Yang JD, Kim WR, Coelho R, Mettler TA, Benson JT, Sanderson SO, Therneau TM, Kim B and Roberts LR: Cirrhosis is present in most patients with hepatitis B and hepatocellular carcinoma. Clin Gastroenterol Hepatol 9: 64-70, 2011.

22. Llovet JM, Ricci S, Mazzaferro V, Hilgard P, Gane E, Blanc JF, de Oliveira AC, Santoro A, Raoul JL, Forner A, et al: Sorafenib in advanced hepatocellular carcinoma. N Engl J Med 359: 378-390, 2008

23. Dotto GP and Rustgi AK: Squamous cell cancers: A unified perspective on biology and genetics. Cancer Cell 29: 622-637, 2016.

24. Herraez E, Lozano E, Macias RI, Vaquero J, Bujanda L, Banales JM, Marin JJ and Briz O: Expression of SLC22A1 variants may affect the response of hepatocellular carcinoma and cholangiocarcinoma to sorafenib. Hepatology 58: 1065-1073 2013.

25. Chaisaingmongkol J, Budhu A, Dang H, Rabibhadana S, Pupacdi B, Kwon SM, Forgues M, Pomyen Y, Bhudhisawasdi V, Lertprasertsuke $\mathrm{N}$, et al: Common molecular subtypes among asian hepatocellular carcinoma and cholangiocarcinoma. Cancer Cell 32: 57-70.e3, 2017

26. Helleday T, Eshtad S and Nik-Zainal S: Mechanisms underlying mutational signatures in human cancers. Nat Rev Genet 15: 585-598, 2014.

27. Totoki Y, Tatsuno K, Yamamoto S, Arai Y, Hosoda F, Ishikawa S, Tsutsumi S, Sonoda K, Totsuka H, Shirakihara T, et al High-resolution characterization of a hepatocellular carcinoma genome. Nat Genet 43: 464-469, 2011.

28. Ong CK, Subimerb C, Pairojkul C, Wongkham S, Cutcutache I, $\mathrm{Yu}$ W, McPherson JR, Allen GE, Ng CC, Wong BH, et al: Exome sequencing of liver fluke-associated cholangiocarcinoma. Nat Genet 44: 690-693, 2012.
29. Dong H, Zhang L, Qian Z, Zhu X, Zhu G, Chen Y, Xie X, Ye Q, Zang J, Ren Z and Ji Q: Identification of HBV-MLL4 integration and its molecular basis in chinese hepatocellular carcinoma. PLoS One 10: e0123175, 2015.

30. Li X, Zhang J, Yang Z, Kang J, Jiang S, Zhang T, Chen T, Li M, Lv Q, Chen X, et al: The function of targeted host genes determines the oncogenicity of HBV integration in hepatocellular carcinoma. J Hepatol 60: 975-984, 2014.

31. Lee YY, Mok MT and Cheng AS: Dissecting the pleiotropic actions of HBx mutants against hypoxia in hepatocellular carcinoma. Hepatobiliary Surg Nutr 3: 95-97, 2014.

32. Lara-Pezzi E, Majano PL, Yáñez-Mó M, Gómez-Gonzalo M, Carretero M, Moreno-Otero R, Sánchez-Madrid F and López-Cabrera M: Effect of the hepatitis B virus HBx protein on integrin-mediated adhesion to and migration on extracellular matrix. J Hepatol 34: 409-415, 2001.

33. Robert C, Long GV, Brady B, Dutriaux C, Maio M, Mortier L, Hassel JC, Rutkowski P, McNeil C, Kalinka-Warzocha E, et al: Nivolumab in previously untreated melanoma without BRAF mutation. N Engl J Med 372: 320-330, 2015.

34. Borghaei H, Paz-Ares L, Horn L, Spigel DR, Steins M, Ready NE, Chow LQ, Vokes EE, Felip E, Holgado E, et al: Nivolumab versus docetaxel in advanced nonsquamous non-small-cell lung cancer. N Engl J Med 373: 1627-1639, 2015.

35. Garon EB, Rizvi NA, Hui R, Leighl N, Balmanoukian AS, Eder JP, Patnaik A, Aggarwal C, Gubens M, Horn L, et al: Pembrolizumab for the treatment of non-small-cell lung cancer. N Engl J Med 372: 2018-2028, 2015.

36. Motzer RJ, Escudier B, McDermott DF, George S, Hammers HJ, Srinivas S, Tykodi SS, Sosman JA, Procopio G, Plimack ER, et al: Nivolumab versus everolimus in advanced renal-cell carcinoma. N Engl J Med 373: 1803-1813, 2015.

37. Rizvi NA, Hellmann MD, Snyder A, Kvistborg P, Makarov V, Havel JJ, Lee W, Yuan J, Wong P, Ho TS, et al: Cancer immunology. Mutational landscape determines sensitivity to PD-1 blockade in non-small cell lung cancer. Science 348: 124-128, 2015.

38. El-Khoueiry AB, Sangro B, Yau T, Crocenzi TS, Kudo M, Hsu C, Kim TY, Choo SP, Trojan J, Welling TH Rd, et al: Nivolumab in patients with advanced hepatocellular carcinoma (CheckMate 040): An open-label, non-comparative, phase $1 / 2$ dose escalation and expansion trial. Lancet 389: 2492-2502, 2017. 